University of Wollongong

Research Online

Australian Institute for Innovative Materials -

Papers

Australian Institute for Innovative Materials

$1-1-2016$

\title{
Aqueous electrosynthesis of an electrochromic material based water- soluble EDOT-MeNH2 hydrochloride
}

Hui Sun

Jiangxi Science and Technology Normal University

Long Zhang

University of Wollongong, Iz898@uowmail.edu.au

Liqi Dong

Jiangxi Science and Technology Normal University

Xiaofei Zhu

Jiangxi Science and Technology Normal University

Shouli Ming

Jiangxi Science and Technology Normal University

See next page for additional authors

Follow this and additional works at: https://ro.uow.edu.au/aiimpapers

Part of the Engineering Commons, and the Physical Sciences and Mathematics Commons

Research Online is the open access institutional repository for the University of Wollongong. For further information contact the UOW Library: research-pubs@uow.edu.au 


\title{
Aqueous electrosynthesis of an electrochromic material based water-soluble EDOT-MeNH2 hydrochloride
}

\author{
Abstract \\ 2'-Aminomethyl-3,4-ethylenedioxythiophene (EDOT-MeNH2) showed unsatisfactory results when its \\ polymerization occurred in organic solvent in our previous report. Therefore, a water-soluble EDOT \\ derivative was designed by using hydrochloric modified EDOT-MeNH2 $($ EDOT-MeNH2 $\cdot \mathrm{HCl})$ and \\ electropolymerized in aqueous solution to form the corresponding polymer with excellent electrochromic \\ properties. Moreover, the polymer was systematically explored, including electrochemical, optical \\ properties and structure characterization. Cyclic voltammetry showed low oxidation potential of EDOT- \\ $\mathrm{MeNH} 2 \cdot \mathrm{HCl}(0.85 \mathrm{~V})$ in aqueous solution, leading to the facile electrodeposition of uniform the polymer \\ film with outstanding electroactivity. Compared with poly(2'-aminomethyl-3,4-ethylenedioxythiophene) \\ (PEDOT-MeNH2), poly(2'-aminomethyl-3,4-ethylenedioxythiophene salt) (PEDOT-MeNH3 +A-) revealed \\ higher efficiencies (156 cm2 C-1), lower bandgap (1.68 eV), and faster response time (1.4 s). Satisfactory \\ results implied that salinization can not only change the polymerization system, but also adjust the \\ optical absorption, thereby increase the electrochromic properties.
}

\section{Keywords}

soluble, edot, aqueous, electrosynthesis, electrochromic, menh2, material, hydrochloride, water

Disciplines

Engineering | Physical Sciences and Mathematics

\section{Publication Details}

Sun, H., Zhang, L., Dong, L., Zhu, X., Ming, S., Zhang, Y., Xing, H., Duan, X. \& Xu, J. (2016). Aqueous electrosynthesis of an electrochromic material based water-soluble EDOT-MeNH2 hydrochloride. Synthetic Metals, 211 147-154.

\section{Authors}

Hui Sun, Long Zhang, Liqi Dong, Xiaofei Zhu, Shouli Ming, Youshan Zhang, Huakun Xing, Xuemin Duan, and Jingkun Xu 


\section{Aqueous electrosynthesis of an electrochromic material based water- soluble EDOT-MeNH 2 hydrochloride}

Hui Sun ${ }^{\mathrm{a}}$, Long Zhang ${ }^{\mathrm{b}}$, Liqi Donga ${ }^{\mathrm{a}}$ Xiaofei Zhu ${ }^{\mathrm{a}}$, Shouli Minga , Youshan Zhanga Huakun Xing ${ }^{\mathrm{a}}$, Xuemin Duan ${ }^{\mathrm{a} *}$, Jingkun $\mathrm{Xu}^{\mathrm{a} *}$

a School of Pharmacy, Jiangxi Science \& Technology Normal University, Nanchang, 330013, P R China

${ }^{\mathrm{b}}$ Intelligent Polymer Research Institute, University of Wollongong, Wollongong, NSW, 2522, Australia

*: Corresponding authors. Tel.: +86-791-83802632; Fax: +86-791-83802632.

E-mail: duanxuemin@126.com,xujingkun@tsinghua.org.cn.

ABSTRACT: 2'-Aminomethyl-3,4-ethylenedioxythiophene (EDOT-MeNH${ }_{2}$ ) showed unsatisfactory results when its polymerization occurred in both organic solvent and aqueous solution published in our previous work. Therefore, a novel water-soluble EDOT derivative was designed by using hydrochloric modified EDOT-MeNH${ }_{2}$ (EDOT$\mathrm{MeNH}_{2} \cdot \mathrm{HCl}$ ) and electropolymerized in aqueous solution to form the corresponding polymer with excellent electrochromic properties. Moreover, the polymer was systematically explored, including electrochemical and optical properties, structure characterization, thermal stability and morphology. Cyclic voltammetry showed low oxidation potential of EDOT-MeNH${ }_{2} \cdot \mathrm{HCl}(0.85 \mathrm{~V})$ in aqueous solution, leading to the facile electrodeposition of uniform the polymer film with outstanding electroactivity. Compared with poly(2'-aminomethyl- 3,4-ethylenedioxythiophene) (PEDOT-MeNH 2$)$, $\operatorname{poly}(2$ '-aminomethyl -3,4-ethylenedioxythiophene hydrochloride) (PEDOT-MeNH $2 \bullet \mathrm{HCl})$ revealed higher efficiencies $\left(156 \mathrm{~cm}^{2} \mathrm{C}^{-1}\right)$, lower bandgap $(1.68 \mathrm{eV})$, and faster 
response time $(1.4 \mathrm{~s})$. Satisfactory results implied that salinization can not only change the polymerization system, but also adjust the optical absorption, thereby increase the electrochromic properties.

Keywords: Conducting polymer; aqueous solution; electrochemical polymerization; PEDOT derivative; electrochromic

\section{Introduction}

Electrochromism can be defined as the reversible change in optical properties of a material resulting from electrochemically induced redox states [1,2]. A wide variety of electrochromic materials are presently known, ranging from metal oxides and mixedvalence metal complexes to organic molecules and conjugated polymers [3]. In recent years, conjugated polymers have gained a lot of attention due to their several advantages over other types of electrochromes, such as low cost, processability, high optical contrast ratio, multi-colors with the same material, high stability and long cycle life with fast response time $[4,5]$.

Among numerous conducting polymers candidates, many electrochromic devices based on poly(3,4-ethylenedioxythiophene) (PEDOT) and its composite have been developed due to innovative polymeric backbone possessing electron-rich nature and inhibiting $\alpha, \beta$ and $\beta, \beta$ - cross-links on polymerization, easy processability (PEDOT:PSS), reversible switching between two redox states, and high chemical stability [6-9]. For further improving electrochromic performance of PEDOT and its derivatives, researches therefore designed a series of strategies including modify the structure through introducing substituents, constructing network film through secondary polymerization, changing the polymeric solvent-electrolyte systems and something like that [10-13]. For 
example, Reynolds's [14-16] and Havinga's [17] groups have reported the first neutralstate solution contained PEDOT derivatives, which were obtained by the method of introduction of solubilizing side chains to the ethylenedioxy bridge of PEDOT.

Significantly, electropolymerization system plays an important role in polymerization of 3,4-ethylenedioxythiophene (EDOT) and its derivatives [18, 19]. It's worth noting that most electropolymerization systems are limited to organic solvents [11, 20-24], which exhibit some shortcomings such as environmental pollution, insecurity, energy shortage etc. Aqueous solution, as a promising "green" alternative solvent medium to traditional volatile and toxic solvents, is beneficial from a cost, handling, environmentally friendly, and safety point of view. Aqueous solution has been not only used as basic solvent system in the field of biosensor since water is the ideal media for biosystems [25, 26], but also plays active roles in lithium ion batteries with the advantages of low cost, easy performance, and intrinsic safety $[27,28]$. However, there are relatively few researches on electrosynthesis and application of polymers in aqueous solution. The key to realize the aim of polymerization in aqueous medium is to increase the water solubility of the precursors.

Salinization, as a simple method for modification, can increase the water solubility of the precursors as well as change the electron density of the conjugated structure, and thereby change the polymerization conditions and photoelectric properties. Reynolds et al. prepared the electrochromic properties of films obtained from the water-soluble poly(4(2,3-dihydrothieno [3,4-b]-[1,4]dioxin-2-yl-methoxy) -1-butanesulfonic acid, sodium salt) (PEDOT-S) and poly(allylamine hydrochloride) [29, 30] in aqueous solution. This method modified PEDOT with salt group provided a simple means of displaying fast 
switching time and high coloration efficiency and had been found effective in electrochromic devices [31].

Recently, we also developed a typical EDOT derivative as promising electrochromic material, aminomethyl functionalized EDOT (EDOT-MeNH 2$)[32,33]$. However, the electrosynthesis of poly(2'-aminomethyl-3,4-ethylenedioxythiophene) (PEDOT-MeNH 2 ) was not ideal in traditional organic solvent system (dichloromethane) unless adding boron trifluoride diethyl etherate, which is water-sensitive and results in the decrease of the polymer quality easily during the process of electrochemical polymerization.

Considering the special property on forming salt easily of amino group, our ongoing interest in PEDOT- $\mathrm{MeNH}_{2}$ prompted us to improve its polymerization system and electrochromic properties by designing EDOT- $\mathrm{MeNH}_{2}$ into the form of hydrochloride. Moreover, the electrochemical polymerization of 2'-aminomethyl- 3,4ethylenedioxythiophene hydrochloride $\left(\mathrm{EDOT}-\mathrm{MeNH}_{2} \bullet \mathrm{HCl}\right)$ in aqueous solution was studied systematically and high-quality poly(2'-aminomethyl-3,4ethylenedioxythiophene hydrochloride) (PEDOT-MeNH${ }_{2} \bullet \mathrm{HCl}$ ) film was easily obtained. Furthermore, the electrochemical behavior, structural characterization, thermal stability, morphology, spectroelectrochemistry, and electrochromic performance of the as-prepared PEDOT- $\mathrm{MeNH}_{2} \cdot \mathrm{HCl}$ were also explored.

\section{Experimental}

\subsection{Chemicals}

2'-Aminomethyl-3,4-ethylenedioxythiophene (EDOT- $\mathrm{MeNH}_{2}$ ) was synthesized as previously described [32]. Dichloromethane $\left(\mathrm{CH}_{2} \mathrm{Cl}_{2}, \mathrm{AR}\right)$ was purchased from Tianjin Damao Chemical Reagent Factory. Methanol $\left(\mathrm{CH}_{3} \mathrm{OH}, \mathrm{AR}\right)$, acetone $\left(\mathrm{CH}_{3} \mathrm{COCH}_{3}, \mathrm{AR}\right)$ 
and dimethyl sulfoxide (DMSO, AR) were purchased from Tianjin Bodi Chemicals Co. Ltd. Concentrated hydrochloric acid ( $\mathrm{HCl}, 98 \%$, Xilong Chemical) was used as received. Perchloric acid $\left(\mathrm{HClO}_{4}, \mathrm{AR}\right)$ was purchased from Tianjin Eastern Chemical Works and used as received. Doubly distilled water was used throughout the work.

2.2. Synthesis of 2'-aminomethyl-3,4-ethylenedioxythiophene hydrochloride (EDOT$\mathrm{MeNH}_{2} \bullet \mathrm{HCl}$ ) [34]

As shown in Scheme 1, EDOT-MeNH $2(0.12 \mathrm{~g}, 0.70 \mathrm{mmol})$ was dissolved in $\mathrm{H}_{2} \mathrm{O} / \mathrm{CH}_{3} \mathrm{OH} / \mathrm{CH}_{3} \mathrm{COCH}_{3}=1: 5: 10$ mixture $(6 \mathrm{~mL})$. Then, $66 \mu \mathrm{L}$ concentrated hydrochloric acid was added, and the mixture was refluxed for $24 \mathrm{~h}$. After reaction, the aqueous phase was extracted with $\mathrm{CH}_{2} \mathrm{Cl}_{2}(3 \times 6 \mathrm{~mL})$ and the combined organic layers were discarded. After evaporation of the inorganic phase, the remaining clear crystal (0.133 g, yield 88.7\%) was obtained. ${ }^{1} \mathrm{H}$ NMR (400 MHz, DMSO- $\left.d_{6}, \mathrm{ppm}\right): \delta 8.44$ (s, 3H), $6.74(\mathrm{~s}, 2 \mathrm{H}), 4.09-4.56(\mathrm{~m}, 3 \mathrm{H}), 3.09-3.30(\mathrm{~m}, 2 \mathrm{H})$.

\subsection{Electrochemical polymerization}

All electrochemical tests and polymerizations were performed in a one-compartment cell with a model 263A potentiostat/galvanostat (EG\&G Princeton Applied Research) under computer control. For electrochemical examinations, the working and counter electrodes were typically both Pt wires of $1 \mathrm{~mm}$ diameter. They were placed $5 \mathrm{~mm}$ apart during the tests. To obtain a sufficient amount of the polymer films for characterization, a Pt sheet or an ITO-coated glass with a surface area of $3 \mathrm{~cm}^{2}$ was employed as the working electrode, and another Pt sheet $(3 \mathrm{~cm} \times 2 \mathrm{~cm})$ was used as the counter electrode. These electrodes were carefully polished with 1500 mesh abrasive paper (for ITO, they were immersed in ethanol for $6 \mathrm{~h}$ and then cleaned by ultrasonic wave for $15 \mathrm{~min}$ ), 
cleaned successively by water and acetone, and dried in air before each experiment. An $\mathrm{Ag} / \mathrm{AgCl}$ electrode directly immersed in the solution served as the reference electrode, and it revealed sufficient stability during the experiments. The typical electrolytic solution was $\mathrm{H}_{2} \mathrm{O}-\mathrm{HClO}_{4}(1.0 \mathrm{M})$ containing $0.01 \mathrm{M}$ monomer. All solutions were deaerated by a dry nitrogen stream (more than $20 \mathrm{~min}$ ) and maintained under a slight overpressure throughout the experiments to avoid the effect of oxygen.

The polymer film was grown potentiostatically at optimized potentials higher than the onset oxidation potentials in $\mathrm{H}_{2} \mathrm{O}-\mathrm{HClO}_{4}(1.0 \mathrm{M})$. Its thickness was controlled by the total charge passed through the cell, which was read directly from the current-time (I-t) curves by computer. After polymerization, the polymer film was washed repeatedly with $\mathrm{H}_{2} \mathrm{O}$ in order to remove the electrolyte and oligomers. Finally, the polymer was dried at $60{ }^{\circ} \mathrm{C}$ under vacuum for $24 \mathrm{~h}$.

\subsection{Characterization}

The ${ }^{1} \mathrm{H}$ NMR spectra were recorded on a Bruker AV 400 NMR spectrometer with $d_{6^{-}}$ DMSO as the solvent and tetramethylsilane as an internal standard (TMS, singlet, chemical shift: $0.0 \mathrm{ppm}$ ). Electrochemical, spectroelectrochemical and kinetic studies were carried out on a Model 263 potentiostat-galvanostat (EG\&G Princeton Applied Research) and a Perkin-Elmer Lambda 900 Ultraviolet-visible Near-Infrared spectrophotometer under computer control. Infrared spectra were measured by a Bruker Vertex 70 Fourier-transform infrared (FT-IR) spectrometer with samples in $\mathrm{KBr}$ pellets. Scanning electron microscopy (SEM) measurements were taken with a VEGAIILSU scanning electron microscope (Tescan). Thermogravimetric (TG) analysis and differential thermogravimetric (DTG) analysis were performed with a Pyris Diamond 
TG/DTA thermal analyzer (PerkinElmer) under a nitrogen stream form 290 to $900 \mathrm{~K}$ with a heating rate of $10 \mathrm{~K} \mathrm{~min}^{-1}$.

Spectroelectrochemical measurements were carried out to investigate the absorption spectra of the polymer films under an applied potential. The spectroelectrochemical cell consists of a quartz cell, an $\mathrm{Ag} / \mathrm{AgCl}$ wire (RE), a Pt wire (CE), and an ITO/glass as the transparent working electrode (WE). All measurements were carried out in monomer-free $\mathrm{H}_{2} \mathrm{O}-\mathrm{HClO}_{4}(1.0 \mathrm{M})$. The quartz cell filled with monomer-free $\mathrm{H}_{2} \mathrm{O}-\mathrm{HClO}_{4}(1.0 \mathrm{M})$ and ITO-coated glass without a deposited film were used as the background for spectroelectrochemical measurements.

The change in optical density $(\triangle O D)$ at a specific wavelength $\left(\lambda_{\max }\right)$ is determined by the $\% T$ values of electrochemically oxidized and neutral films using equation (1) [35]:

$$
\triangle O D=\log \left(T_{\text {ox }} / T_{\text {red }}\right)
$$

The coloration efficiency $(C E)$ is defined as the relation between the injected/ejected charge as a function of electrode area $\left(Q_{\mathrm{d}}\right)$ and the change in optical density $(\triangle O D)$ at a specific dominant wavelength $\left(\lambda_{\max }\right)$, as illustrated by equation (2) [36]:

$$
C E=\triangle O D / Q_{\mathrm{d}}
$$

\section{Results and discussion}

\subsection{Electrochemical polymerization of EDOT-MeNH $\mathrm{H}_{2} \bullet \mathrm{HCl}$}

The electropolymerization performance of EDOT- $\mathrm{MeNH}_{2} \bullet \mathrm{HCl}(0.01 \mathrm{M})$ was examined via cyclic voltammetry $(\mathrm{CV})$ in $\mathrm{H}_{2} \mathrm{O}-\mathrm{HClO}_{4}(1.0 \mathrm{M})$ system. The onset oxidation potential $\left(E_{\text {onset }}\right)$ of EDOT-MeNH $\mathrm{N}_{2} \bullet \mathrm{HCl}$ was found to be $0.85 \mathrm{~V}$ as can be seen from the inset of Fig. 1, which confirmed the monomer was easily oxidized in water system. By the force of contrast, the value was lower than that of EDOT- $\mathrm{MeNH}_{2}$ in $\mathrm{CH}_{2} \mathrm{Cl}_{2}-\mathrm{Bu}_{4} \mathrm{NPF}_{6}$ 
but a litter higher than that in $\mathrm{CH}_{2} \mathrm{Cl}_{2}-\mathrm{Bu}_{4} \mathrm{NPF}_{6}(0.1 \mathrm{M})$ system containing $2 \%$ boron trifluoride diethyl etherate [33].

Fig. 1 showed the cyclic voltammograms $(\mathrm{CVs})$ corresponding to the potentiodynamic electropolymerization of EDOT- $\mathrm{MeNH}_{2} \bullet \mathrm{HCl}$. On the first scan, the formation of the current loop over $E_{\text {onset }}$ was characteristic for the nucleation process. Also, the increase of anodic and cathodic peak current densities in the CVs implied an increasing amount of polymer film on the electrode surface. Visual inspection during CV experiments revealed the formation of compact and homogeneous polymer films on the electrode surface. The behaviors demonstrated EDOT- $\mathrm{MeNH}_{2} \bullet \mathrm{HCl}$ could be electropolymerized to form the electroactive polymer in water system. The broad redox waves of the polymer may be ascribed to the wide distribution of polymer chain length or the conversion of conductive species on the polymer main chain from a neutral to a metallic state [37]. The potential shift of current density peaks provided information about the increase in the electrical resistance of the polymer film and the overpotential needed to overcome this resistance, which is characteristic of conducting polymers during potentiodynamic polymerization.

Potentiostatic electrolysis was employed to prepare PEDOT-MeNH $\mathrm{N}_{2} \cdot \mathrm{HCl}$ film for characterization. To optimize the applied potential for polymerization, a set of current transients during the electropolymerization at different applied potentials were recorded. Considering the overall factors affecting the quality of the as formed polymer films, such as moderate polymerization rate, negligible overoxidation, regular morphology, and good adherence against the working electrode, the selected applied potential were $1.00 \mathrm{~V}$ for the electropolymerization of EDOT- $\mathrm{MeNH}_{2} \bullet \mathrm{HCl}$.

\subsection{Structural characterization}


FT-IR spectra can provide much structural information for newly-obtained polymers. A comparison of the evolution of vibrational modes appearing in polymers and in some simpler related molecules acting as references usually facilitates the interpretation of their experimental absorption spectra. FT-IR spectra of the monomer and its corresponding polymer were recorded to elucidate their structure and interpret the polymerization mechanism (Fig. 2). As can be seen, the absorption bands in the spectrum of the dedoped polymer were obviously broadened in comparison with those of monomer. This was not only attributable to the wide conjugated chain length distribution of the polymer but also the chemical defects on the polymer chain resulting from the over oxidation of the polymer [38].

The details of the band assignments of monomer and dedoped polymer were given in Table 1. The peak at $3005 \mathrm{~cm}^{-1}$ for EDOT-MeNH${ }_{2} \cdot \mathrm{HCl}$ (Fig. $2 a$ ) was produced by $\mathrm{C}-\mathrm{H}$ vibration of 2,5-positions in the thiophene ring. This peak was retained in the monomer (Fig. 2a) but disappeared in the electrochemical polymerized sample (Fig. 2b). This indicated that the electropolymerization mainly occurred at the 2,5-positions of the thiophene ring. From Fig. 2 and Table 1, the $-\mathrm{NH}_{3}{ }^{+}$in-plane vibration existed in the spectra of monomer $\left(3437 \mathrm{~cm}^{-1}\right)$ and polymer $\left(3475 \mathrm{~cm}^{-1}\right)$, indicating that $-\mathrm{NH}_{3}{ }^{+}$was not destroyed during electrochemical polymerization. In the case of PEDOT-MeNH${ }_{2} \bullet \mathrm{HCl}$, the peaks at $1512 \mathrm{~cm}^{-1}$ could be assigned to $\mathrm{C}=\mathrm{C}$ stretching vibration. Further, the vibration at $1325 \mathrm{~cm}^{-1}$ is ascribed to the stretching mode of single $\mathrm{C}-\mathrm{C}$ bond. The vibration mode from the $\mathrm{C}-\mathrm{S}$ bond in the thiophene ring can be found at $937 \mathrm{~cm}^{-1}$. For the ethyleneoxythia group, the absorption peaks originated from the $\mathrm{CH}_{2}$ symmetric and asymmetric stretching vibrations could be observed at $2895 \mathrm{~cm}^{-1}$. In addition, the peak at 
$1201 \mathrm{~cm}^{-1}$ demonstrated the C-O-C vibration in the ethyleneoxythia ring. All results confirmed that the structure of EDOT- $\mathrm{MeNH}_{2} \cdot \mathrm{HCl}$ was not destroyed during the electrochemical polymerization process.

\subsection{Surface morphology}

Scanning electron microscopy (SEM) has been one of the most widely used techniques in the study of the morphology of polymeric materials for analyzing their constituents and texture. Besides, the surface microscopy of conducting polymers is closely related to their properties, such as electrical conductivity, redox activity and stability, etc. Therefore, the surface of the doped and dedoped polymer films deposited electrochemically on the ITO electrodes was observed by SEM (Fig. 3). Microscopically, even at high magnifications, the surface of the doped PEDOT-MeNH${ }_{2} \bullet \mathrm{HCl}$ films (Fig. $3 A$ ) obtained from $\mathrm{H}_{2} \mathrm{O}-\mathrm{HClO}_{4}(1.0 \mathrm{M})$ solution was rather smooth, homogeneous, and continuous with few defects. The morphology of compact polymer films may improve their electrical conductivity and electron transfer capability; it also made them good candidates for applications in ion-selective electrodes, ion-sieving films, matrices for hosting catalyst particles, etc $[39,40]$. After dedoping at a negative constant applied potential $(-0.4 \mathrm{~V})$, the main morphology of PEDOT-MeNH $\mathrm{H}_{2} \cdot \mathrm{HCl}$ became rougher and less uniform (Fig. $3 B$ ). These differences between the doped and dedoped polymer films were mainly due to the migration of counter anions out of the polymer films and their gradual solubility from the electrode to the solution during the dedoping processes [41], which broke the relatively smooth surfaces of doped polymer films.

\subsection{Thermal analysis}


The thermal stability of conducting polymers is very important for their potential applications. Thermogravimetric (TG) analysis is a significant dynamic way of detecting the degradation behaviors. To investigate the thermal stability of the new polymer, TG analytical experiment of PEDOT-MeNH $\mathrm{H}_{2} \bullet \mathrm{HCl}$ polymer was performed under a nitrogen stream at the heating rate of $10 \mathrm{~K} \mathrm{~min}^{-1}$. As shown in Fig. 4, it could be clearly observed that there were three-step weight losses for the polymer. The polymer initially underwent a small weight decrease (about $4.76 \%$ ) at relatively low temperature (from 284 to $348 \mathrm{~K}$ ), which may be attributed to moisture evaporation and a few monomers trapped in the polymer. With the gradual increasing of the temperature, a prominent weight loss step (about $52.66 \%$ ) was clearly found at $348 \mathrm{~K}<\mathrm{T}<565 \mathrm{~K}$, which were essentially due to the oxidizing decomposition of the skeletal PEDOT- $\mathrm{MeNH}_{2} \bullet \mathrm{HCl}$ backbone chain structures. Simultaneously, the DTG curve showed that the corresponding maximal decomposition occurred at $507 \mathrm{~K}$. Such an onset temperature of degradation was lower compared to those reported PEDOT-MeNH 2 and PEDOT in our previous reports [33, 42]. Such a weight loss was closely related to the overflow of some oligomers or with short chain structure. Secondarily, the degradation between 565 and $877 \mathrm{~K}$ amounting to 18.69\% was probably caused by the oxidizing decomposition of the skeletal PEDOT$\mathrm{MeNH}_{2} \bullet \mathrm{HCl}$ backbone chain structure. In addition, when the temperature reached $877 \mathrm{~K}$, as-formed PEDOT-MeNH${ }_{2} \bullet \mathrm{HCl}$ polymer lost about $76.11 \%$ of its weight.

\subsection{Electrochemistry properties of the polymer}

The electrochemical behaviour of the polymer-modified Pt electrode was studied by CV in monomer-free $\mathrm{H}_{2} \mathrm{O}-\mathrm{HClO}_{4}(1.0 \mathrm{M})$ solution to test their electroactivity and stability. The steady-state $\mathrm{CVs}$ of PEDOT- $\mathrm{MeNH}_{2} \cdot \mathrm{HCl}$ represented broad anodic and cathodic 
peaks whose peak current densities are both proportional to the scan rates (Fig. 5), indicating that the redox process was non-diffusional and the electroactive material was well adhered to the working electrode surface. Furthermore, CVs of the polymer in monomer-free $\mathrm{H}_{2} \mathrm{O}-\mathrm{HClO}_{4}(1.0 \mathrm{M})$ solution (Fig. 5) demonstrated an obvious hysteresis, i.e., there was an obvious difference between the anodic and cathodic peak potentials [43, 44]. The potential shift of redox peaks among CV curves for conducting polymers is hardly explained by conventional kinetic limitations such as ion diffusion or interfacial charge transfer processes. The main reasons that account for this phenomenon are usually as follows: slow heterogeneous electron transfer, local rearrangement of polymer chains, slow mutual transformation of various electronic species, and electronic charging of interfacial exchange corresponding to the metal/polymer and polymer/solution interfaces [43].

It is well known that the stability of conducting polymers is critical for their application in electronic devices $[45,46]$. For that reason, the long-term stability upon cycling of these polymer films deposited on the Pt electrode was investigated by potential scanning between neutral and oxidized states in monomer-free $\mathrm{H}_{2} \mathrm{O}-\mathrm{HClO}_{4}(1.0 \mathrm{M})$ solution (Fig. 6). The number of scanning cycles was 2000 between -0.40 and $0.75 \mathrm{~V}$ at the potential scan rate of $150 \mathrm{mV} \mathrm{s}^{-1}$. From Fig. 6, PEDOT-MeNH${ }_{2} \bullet \mathrm{HCl}$ films could be cycled repeatedly between the conducting (oxidized) and insulating (neutral) states without significant decomposition. After completion of 1000 cycles, PEDOT-MeNH${ }_{2} \bullet \mathrm{HCl}$ was remaining $80.57 \%$. Even after 2000 cycles, the stability of PEDOT-MeNH${ }_{2} \bullet \mathrm{HCl}$ still exhibited about $73.37 \%$ of its original electroactivity. It displayed even better stability 
than PEDOT-MeNH $2(50.43 \%$ after 2000 cycles) [33], which indicates that salinization might be beneficial to the stability of conducting polymer.

\subsection{Spectroelectrochemistry}

For application in devices and high-performance displays, the spectroelectrochemical properties of the polymers should be manifested by changes in the optical absorption spectra under voltage pulses. Therefore, UV-vis spectra of the polymer electrodeposited on ITO-coated glass slides via potential cycling between $-0.5 \mathrm{~V}$ and $0.8 \mathrm{~V}$ were recorded in situ in monomer-free $\mathrm{H}_{2} \mathrm{O}-\mathrm{HClO}_{4}(1.0 \mathrm{M}$ ) solution after neutralization (Fig. 7).

In the neutral form, the film exhibited strong absorption at the wavelength around 603 $\mathrm{nm}$, and the absorption of the as-formed polymer tailed off to $720 \mathrm{~nm}$. The absorption in visible region led to a amaranth coloration. Compared with that of PEDOT-MeNH 2 (the absorption peak around $582 \mathrm{~nm}$ ), PEDOT- $\mathrm{MeNH}_{2} \bullet \mathrm{HCl}$ revealed red shift (about $21 \mathrm{~nm}$ ) in the absorption at the neutral state, probably due to the increase of the conjugated chain length after salinization. The red-shift of the absorption further confirmed EDOT$\mathrm{MeNH}_{2} \cdot \mathrm{HCl}$ could be easily electropolymerized to form high quality film in water system. Moreover, the band gap (extracted from the onset of the $\pi-\pi^{*}$ transition) for the dedoped polymer was calculated as $1.68 \mathrm{eV}(740 \mathrm{~nm})$, which was slightly lower than the reported optical band gap of parent PEDOT-MeNH $2(1.7 \mathrm{eV})$.

The spectroelectrochemistry of $\mathrm{PEDOT}-\mathrm{MeNH}_{2} \cdot \mathrm{HCl}$ films upon oxidation was presented in Fig. 7. Stepwise oxidation of the polymer showed the fading of absorbance at $603 \mathrm{~nm}$ and typical evolution of peaks at more than $730 \mathrm{~nm}$ [47]. As each potential was stepped, the absorption in the visible regime began to decrease, whereas that in the NIR regime increased, indicating the creation of lower energy charge carriers at the expense of 
$\pi-\pi^{*}$ transition [48]. Meanwhile, PEDOT-MeNH${ }_{2} \cdot \mathrm{HCl}$ film changed from amaranth in the reduced state to sky blue in the oxidized state.

\subsection{Electrochromic properties}

Double-potential step chronoabsorptometry of PEDOT-MeNH $2 \cdot \mathrm{HCl}$ film monitored at 602 and $1100 \mathrm{~nm}$ under the applied potentials of -0.5 and $0.8 \mathrm{~V}$ was performed to probe its electrochromic kinetic studies, and the results are shown in Fig. 8. The electrochromic parameters [optical contrast ratio $(\Delta T \%)$, response time, and coloration efficiency $(C E)$ ] of PEDOT-MeNH${ }_{2} \bullet \mathrm{HCl}$ films were summarized in Table 2. The switching time was optimized to yield the maximum transmittance contrast, and the potentials were switched stepwise between neutral and oxidized states with a residence time of $10 \mathrm{~s}$.

The $\Delta T \%$ of PEDOT-MeNH${ }_{2} \cdot \mathrm{HCl}$ was found to be $26.38 \%$ at $602 \mathrm{~nm}$ and $17.47 \%$ at $1100 \mathrm{~nm}$, whereas the optical contrast of PEDOT-MeNH $\mathrm{H}_{2}$ at the charge transfer band $(582 \mathrm{~nm})$ and NIR band $(1050 \mathrm{~nm})$ were $41.8 \%$ and $36.9 \%$, respectively (Table 2$)$. The optical contrast ratios of the PEDOT- $\mathrm{MeNH}_{2} \bullet \mathrm{HCl}$ polymer was much lower than that of PEDOT-MeNH 2 and PEDOT [49]. The phenomenon might be ascribed to the following reasons: (1) due to the introduction of the pendant chain, the doping nature of PEDOT was changed slightly; (2) structural defects could probably be an inevitable factor during the electropolymerization; (3) during the electrochromic tests, the polymer film showed poor adherence against the ITO-glass in comparison with the Pt electrode and some polymer/oligomers dispersed into the solvent.

As for electrochromic applications, response time of polymer is another important parameter since it indicates the speed of ions moving into the polymer chains during the doping process. As illustrated in Fig. 8, the response time required to attain $95 \%$ of total 
transmittance difference was found to be $1.4 \mathrm{~s}$ at $602 \mathrm{~nm}$ and $3.2 \mathrm{~s}$ at $1100 \mathrm{~nm}$ from the reduced state to the oxidized state, which was faster than PEDOT-MeNH $2(582 \mathrm{~nm}, 2.4 \mathrm{~s}$; $1050 \mathrm{~nm}, 5.2 \mathrm{~s}$ ) [33]. The difference can be attributed to the ease of charge transport in the conducting film when it is oxidized. The $C E$ is also an important characteristic for electrochromic materials and obtained for a certain amount of the charge injected in the polymer films as a function of the change in optical density. In this study, $C E$ was measured as $156 \mathrm{~cm}^{2} \mathrm{C}^{-1}$ at $602 \mathrm{~nm}$, which was a little higher than that of PEDOT$\mathrm{MeNH}_{2}\left(152 \mathrm{~cm}^{2} \mathrm{C}^{-1}\right)$ [33] and PEDOT $\left(137 \mathrm{~cm}^{2} \mathrm{C}^{-1}\right)$ [49].

\section{Conclusions}

In summary, in order to improve the polymerization system and electrochromic properties of EDOT-MeNH${ }_{2}$, a water-soluble monomer, EDOT-MeNH${ }_{2} \bullet \mathrm{HCl}$, was synthesized through the method of salinization. Then the novel electrochromic PEDOT$\mathrm{MeNH}_{2} \cdot \mathrm{HCl}$ was easily directly obtained by electropolymerization of monomer in aqueous solution. The polymer was comprehensively investigated including electrochemical, structure characterization, surface morphology, thermal stability, spectroelectrochemical, and electrochromic properties. The polymer showed good electrochemical activity in aqueous solution. PEDOT-MeNH $\mathrm{H}_{2} \bullet \mathrm{HCl}$ was found to exhibit the electrochromic nature by color changing from amaranth to sky blue with favorable

coloration efficiency $\left(156 \mathrm{~cm}^{2} \mathrm{C}^{-1}\right)$ and fast response time $(1.4 \mathrm{~s})$, which enhanced the electrochromic properties of PEDOT-MeNH 2 . Considering all these results, the method of salinization that improved the polymerization system and photoelectric properties of the polymer will hold promise for electrochromic devices and display applications.

\section{Acknowledgements}


The authors would like to acknowledge the financial support of this work by the National Natural Science Foundation of China (51263010, 51303073, 51272096, 51403008), Natural Science Foundation of Jiangxi Province (20142BAB206028, 2014BAB216029) and the Science and Technology Landing Plan of Universities in Jiangxi province (KJLD14069).

\section{References}

[1] A.A. Argun, P.H. Aubert, B.C. Thompson, I. Schwendeman, C.L. Gaupp, J. Hwang, N.J. Pinto, D.B. Tanner, A.G. MacDiarmid, J.R. Reynolds, Chem. Mater. 16 (2004) 4401-4412.

[2] M.M. Verghese, M.K. Ram, H. Vardhan, B.D. Malhotra, Polymer 38 (1997) $1625-1629$.

[3] P.R. Somania, S. Radhakrishnan, Materials Chemistry and Physics 77 (2002) $117-133$.

[4] A. Cihaner, Fatih Alg1, Adv. Funct. Mater. 18 (2008) 3583-3589.

[5] P.M. Beaujuge, J.R. Reynolds, Chem. Rev. 110 (2010) 268-320.

[6] L.B. Groenendaal, F. Jonas, D. Freitag, H. Pielartzik, J.R. Reynolds, Adv. Mater. 12 (2000) 481-494.

[7] L.B. Groenendaal, G. Zotti, P.H. Aubert, S.M. Wavbright, J.R. Reynolds, Adv. Mater. 15 (2003) 855-879.

[8] E. Moczko, G. Istamboulie, C. Calas-Blanchard, R. Rouillon, J. Polym. Sci. Part A: Polym. Chem. 50 (2012) 2286-2292.

[9] T.C. Tsai, T.H. Chen, H.C. Chang, C.H. Chen, Y.C. Huang, W.T. Whang, J. Polym. Sci. Part A: Polym. Chem. 52 (2014) 3303-3306. 
[10] J.A. Kerszulis, K.E. Johnson, M. Kuepfert, D. Khoshabo, A.L. Dyer, J.R. Reynolds, J. Mater. Chem. C 3(2015) 3211-3218.

[11] B. Wang, J. Zhao, C. Cui, R. Liu, J. Liu, H. Wang, H. Liu, Electrochim. Acta 56 (2011) 4819-4827.

[12] L. Qin, J. Xu, B. Lu, Y. Lu, X. Duan, G. Nie, J. Mater. Chem. 22 (2012) 1834518355.

[13] J. Kim, J. You, B. Kim, T. Park, E. Kim, Adv. Mater. 23 (2011) 4168-4173.

[14] S.V. Vasilyeva, P.M. Beaujuge, S. Wang, J.E. Babiarz, V.W. Ballarotto, J.R. Reynolds, ACS Appl. Mater. Interfaces 3 (2011) 1022-1032.

[15] P. Shi, C.M. Amb, E.P. Knott, E.J. Thompson, D.Y. Liu, J. Mei, A.L. Dyer, J.R. Reynolds, Adv. Mater. 22 (2010) 4949-4953.

[16] P.M. Beaujuge, S. Ellinger, J.R. Reynolds, Nat Mater. 7 (2008) 795-799.

[17] E.E. Havinga, C.M. J. Mutsaers, Chem. Mater. 8 (1996) 769-776.

[18] Z. Wang, J. Xu, B. Lu, S. Zhang, L. Qin, D. Mo, S. Zhen, Langmuir 30 (2014) $15581-15589$.

[19] E. Poverenov, M. Li, A. Bitler, M. Bendikov, Chem. Mater. 22 (2010) 4019-4025.

[20] S. Ming, S. Zhen, K. Lin, L. Zhao, J. Xu, B. Lu, ACS Appl. Mater. Interfaces 7 (2015) 11089-11098.

[21] G. Nie, L. Zhou, H. Yang, J. Mater. Chem. 21 (2011) 13873-13880.

[22] S. Golba, M. Łężniak, J. Gabor, T. Flak, Synthetic Met. 199 (2015) 310-318.

[23] K. Lin, S. Zhen, S. Ming, J. Xu, B. Lu, New J. Chem. 39 (2015) 2096-2105.

[24] D. Mo, S. Zhen, J. Xu, W. Zhou, B. Lu, G. Zhang, Z. Wang, S. Zhang, Z. Feng, Synthetic Met. 198 (2014) 19-30 
[25] Y. Lu, Y. Wen, B. Lu, X. Duan, J. Xu, L. Zhang, Y. Huang, Chinese J. Polym. Sci. 30 (2012) 824-836.

[26] Y. Wen, J. Xu, H. He, B. Lu, Y. Li, B. Dong, J. Electroanal. Chem. 634 (2009) $49-58$.

[27] H.Wang, K. Huang, Y. Zeng, S. Yang, L. Chen, Electrochim. Acta 52 (2007) $3280-3285$.

[28] J.W. Lee, S.I. Pyun, Electrochim. Acta 49 (2004) 753-761.

[29] C.A. Cutler, M. Bouguettaya, J.R. Reynolds, Adv. Mater. 14 (2002) 684-688.

[30] C.A. Cutler, M. Bouguettaya, T.S. Kang, J.R. Reynolds, Macromolecules 38 (2005) 3068-3074.

[31] R.H. Karlsson, A. Herland, M. Hamedi, J.A. Wigenius, A. Åslund, X. Liu, M. Fahlman, O. Inganäs, P. Konradsson, Chem. Mater. 21(2009) 1815-1821.

[32] H. Sun, B. Lu, X. Duan, J. Xu, L. Dong, X. Zhu, K. Zhang, D. Hu, S. Ming, Int. J. Electrochem. Sci. 10 (2015) 3236 - 3249.

[33] H. Sun, B. Lu, D. Hu, X. Duan, J. Xu, S. Zhen, K. Zhang, X. Zhu, L. Dong, D. Mo, Chinese J. Polym. Sci. 2015, doi: 10.1007/s10118-015-1693-0

[34] H.J. Schanz, M.A. Linseis, D.G. Gilheany, Tetrahedron: Asymmetry, 14 (2003) $2763-2769$.

[35] C.L. Gaupp, D.M. Welsh, R.D. Rauh, J.R. Reynolds, Chem. Mater. 14 (2002) 3964-3970.

[36] B.D. Reeves, C.R. G. Grenier, A.A. Argun, A. Cirpan, T.D. McCarley, J.R. Reynolds, Macromolecules 37 (2004) 7559-7569.

[37] M. Zhou, J. Heinze, Electrochim. Acta 44 (1999) 1733-1748. 
[38] J. Zhang, C. Liu, G. Shi, Y. Zhao, J. Polym. Sci. Part B: Pol. Phys. 43 (2005) 241251.

[39] J. Lee, Z. Li, M. Hodgson, J. Metson, A. Asadov, W. Gao, Curr. Appl Phys. 4 (2004) 398-401.

[40] M.C. Li, C.A. Ma, B.Y. Liu, Z.M. Jin, Electrochem. Commun. 7 (2005) 209-212.

[41] B. Lu, J. Yan, J. Xu, S. Zhou, X. Hu, Macromolecules 43 (2010) 4599-4608.

[42] S. Zhang, J. Hou, R. Zhang, J. Xu, G. Nie, S. Pu, Eur. Polym. J. 42 (2006) 149160.

[43] G. Inzelt, M. Pineri, J.W. Schultze, M. A. Vorotyntsev, Electrochim. Acta 45 (2000) 2403-2421.

[44] M.A. Vorotyntsev, J.P. Badiali, Electrochim. Acta 39 (1994) 289-306.

[45] H.E. Katz, Chem. Mater. 16 (2004) 4748-4756.

[46] F. Uckert, Y.H. Tak, K. Müllen, H. Bässler, Adv. Mater. 12 (2000) 905-908.

[47] Y.C. Kung, S.H. Hsiao, J. Mater. Chem. 20 (2010) 5481-5492.

[48] C.W. Chang, G.S. Liou, S.H. Hsiao, J. Mater. Chem. 17 (2007) 1007-1015.

[49] A. Elschner, S. Kirchmeyer, W. Lövenich, U. Merker, K. Reuter, PEDOT Principles and applications of an intrinsically conductive polymer, Taylor \& Francis Group: Boca Raton, 2011. 


\section{Figure and table captions:}

Scheme 1 Synthetic route of EDOT- $\mathrm{MeNH}_{2} \cdot \mathrm{HCl}$ and its electrochemical polymerization.

Fig. 1 Successive cyclic voltammograms and anodic polarization curve (inset) of $0.01 \mathrm{M}$ EDOT-MeNH $2 \cdot \mathrm{HCl}$ in $\mathrm{H}_{2} \mathrm{O}-\mathrm{HClO}_{4}(1.0 \mathrm{M})$. Potential scan rate: $100 \mathrm{mV} \mathrm{s}{ }^{-1}$.

Fig. 2 FT-IR spectra of EDOT-MeNH$H_{2} \cdot \mathrm{HCl}$ monomer (a) and the doped PEDOT$\mathrm{MeNH}_{2} \cdot \mathrm{HCl}(\mathrm{b})$.

Fig. 3 SEM images of the doped (A) and dedoped (B) PEDOT-MeNH$\cdot \mathrm{HCl}$ film.

Fig. 4 TG and DTG curves of the doped PEDOT-MeNH $2 \cdot \mathrm{HCl}$ film.

Fig. 5 (A) $\mathrm{CVs}$ of PEDOT-MeNH $2 \cdot \mathrm{HCl}$ in $\mathrm{H}_{2} \mathrm{O}-\mathrm{HClO}_{4}(1.0 \mathrm{M})$ at potential scan rates of $300,275,250,225,200,175,150,125,100,75,50$, and $25 \mathrm{mV} \mathrm{s}^{-1}$. (B) Plots of redox peak current densities vs. potential scan rates. $j_{\mathrm{p}}$ is the peak current densities, $j_{\mathrm{p}, \mathrm{a}}$ and $j_{\mathrm{p}, \mathrm{c}}$ denote the anodic and cathodic peak current densities, respectively.

Fig. 6 Long-term redox stability of PEDOT-MeNH $2 \cdot \mathrm{HCl}$ upon repeated cycling in monomer-free $\mathrm{H}_{2} \mathrm{O}-\mathrm{HClO}_{4}(1.0 \mathrm{M})$ solution at the scan rate of $150 \mathrm{mV} \mathrm{s}^{-1}$.

Fig. 7 Spectroelectrochemistry of PEDOT-MeNH $2 \cdot \mathrm{HCl}$ film on ITO-coated glass in $\mathrm{H}_{2} \mathrm{O}-\mathrm{HClO}_{4}(1.0 \mathrm{M})$ solution at applied potentials from $-0.5 \mathrm{~V}$ to $0.8 \mathrm{~V}$.

Fig. 8 Electrochromic switching and optical absorbance monitored at $602 \mathrm{~nm}$ (A) and $1100 \mathrm{~nm}$ (B) profiles of PEDOT-MeNH $2 \cdot \mathrm{HCl}$ film recorded during double step spectrochronoamperometry between $-0.5 \mathrm{~V}$ and $0.8 \mathrm{~V}$ for the switching time of $10 \mathrm{~s}$. 
Table 1 Assignments of FT-IR spectra of the monomer and the doped PEDOT$\mathrm{MeNH}_{2} \cdot \mathrm{HCl}$.

Table 2 Electrochromic switching and optical absorbance monitored at $602 \mathrm{~nm}$ (A) and $1100 \mathrm{~nm}$ (B) profiles of PEDOT- $\mathrm{MeNH}_{2} \cdot \mathrm{HCl}$ film recorded during double step spectrochronoamperometry between $-0.5 \mathrm{~V}$ and $0.8 \mathrm{~V}$ for the switching time of $10 \mathrm{~s}$.

\section{Figures:}
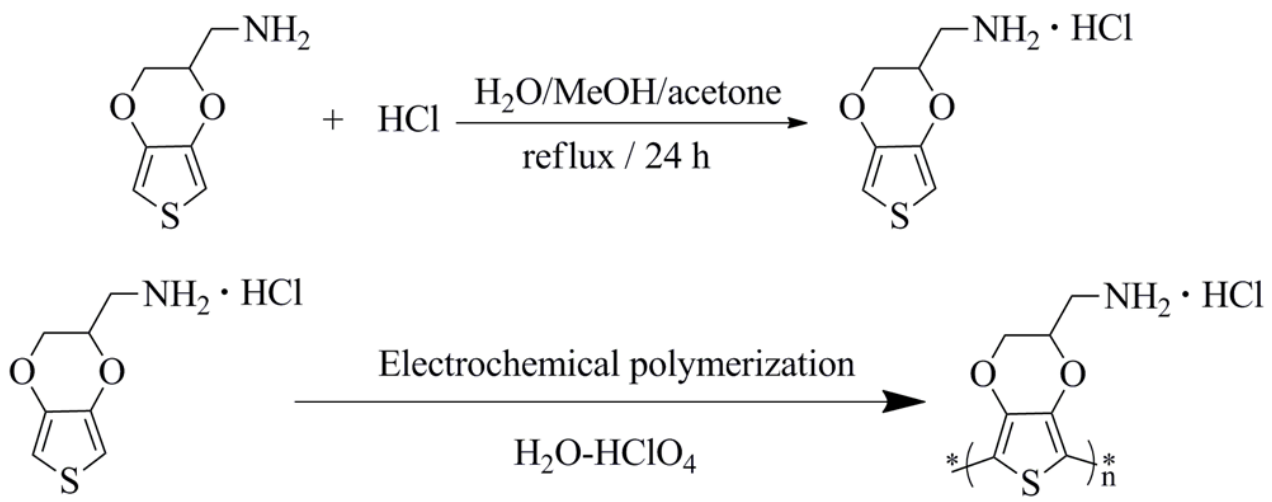

Scheme 1 


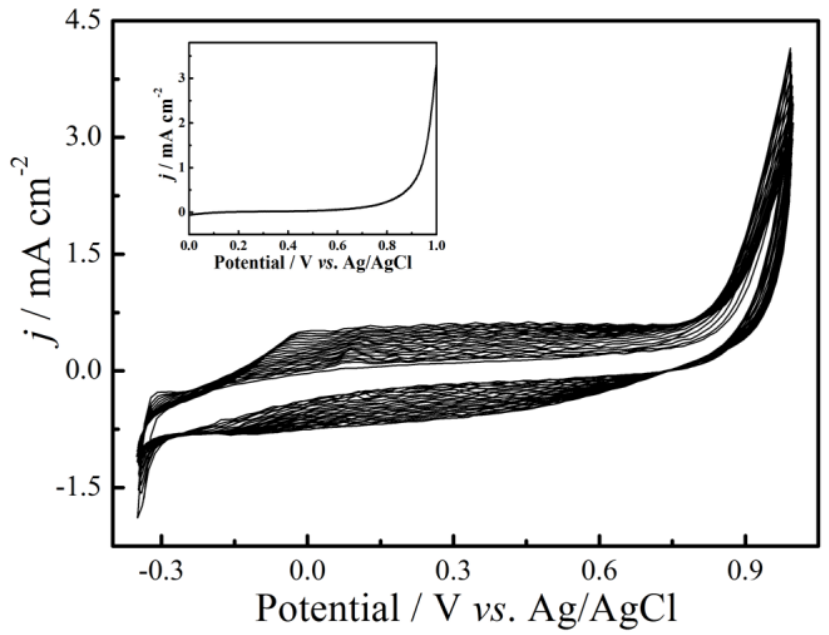

Fig. 1 


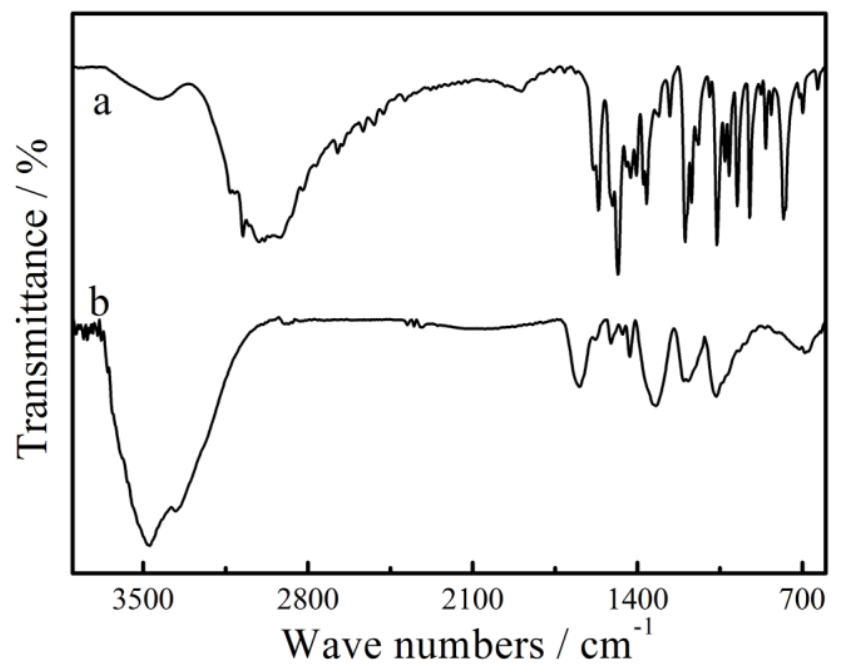

Fig. 2 


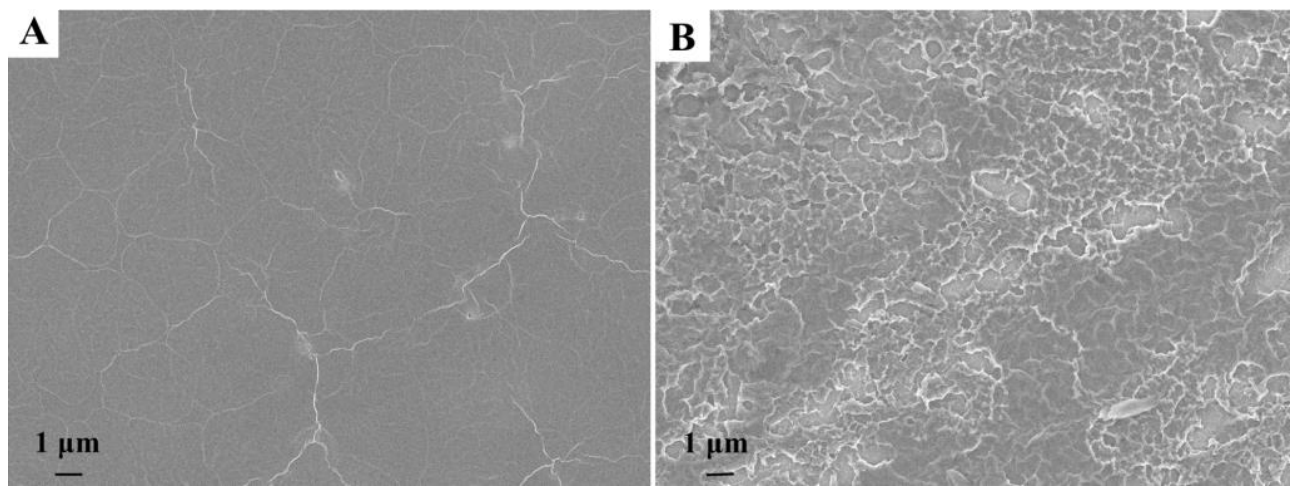

Fig. 3 


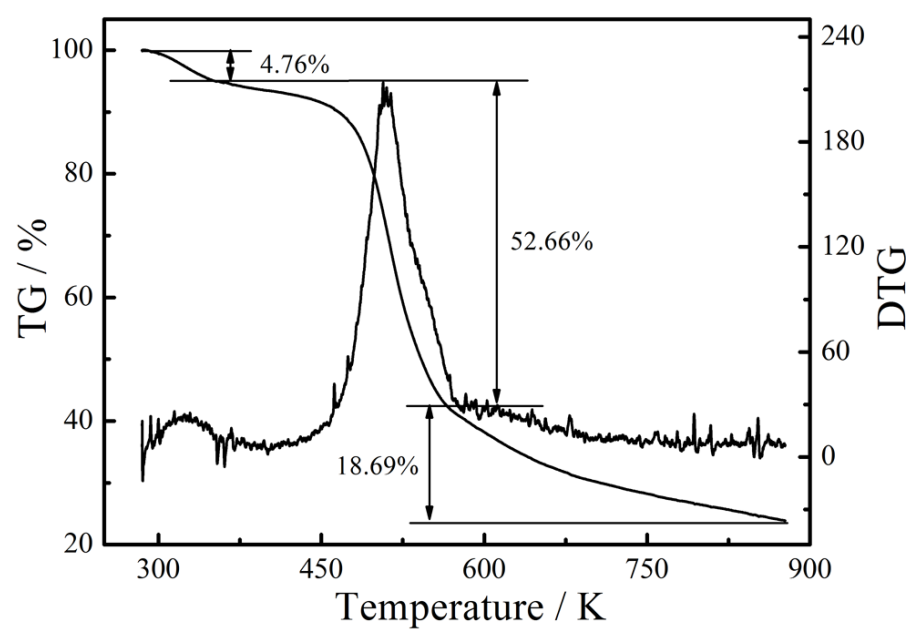

Fig. 4 

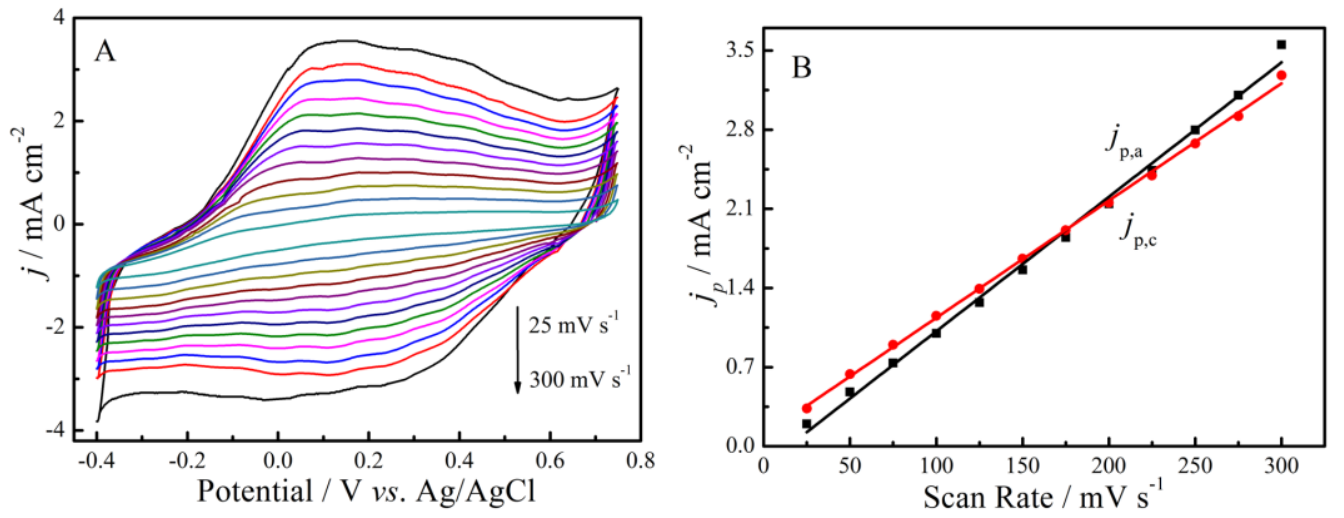

Fig. 5 


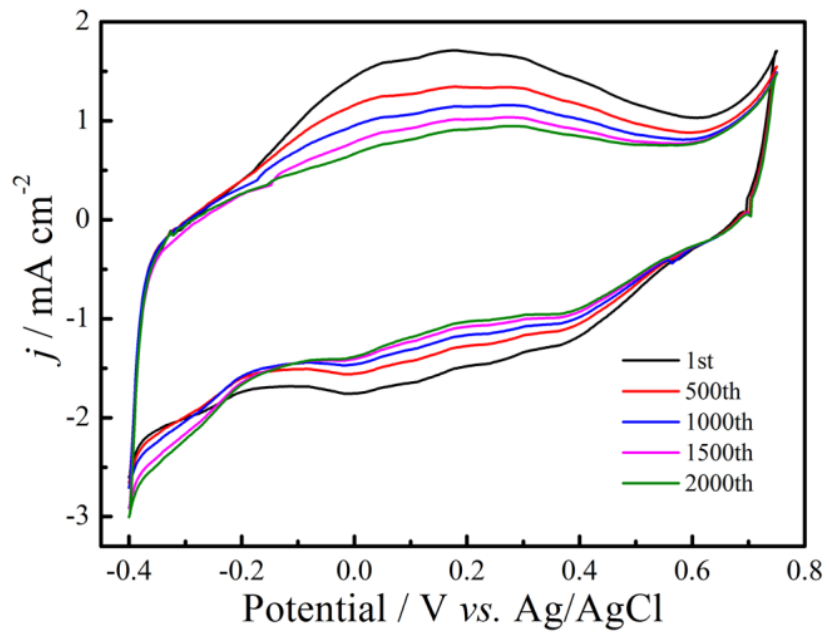

Fig. 6 


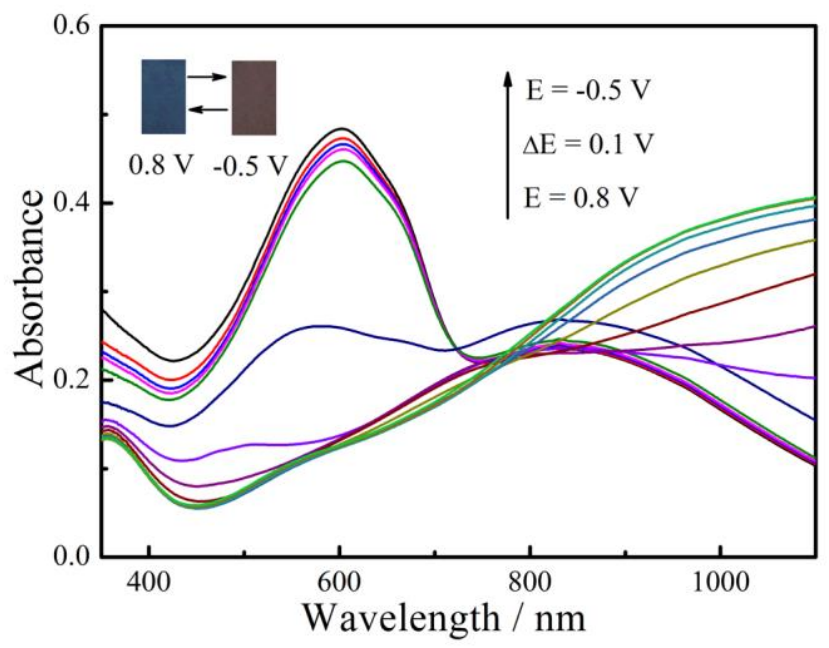

Fig. 7 

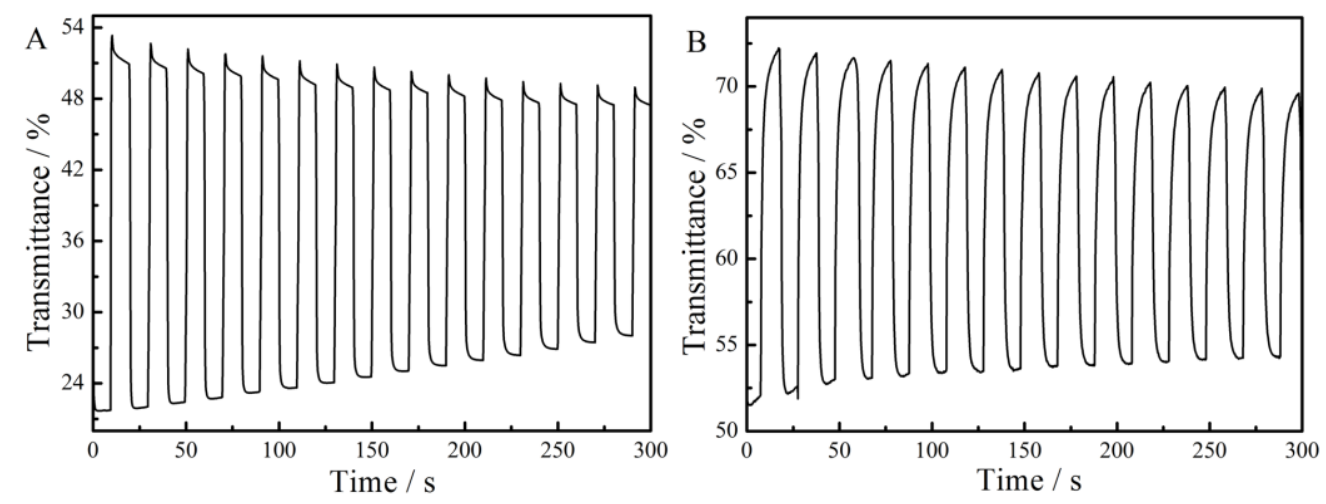

Fig. 8 


\section{Table 1}

\begin{tabular}{|c|c|c|}
\hline \multicolumn{2}{|c|}{ Band $\left(\mathrm{cm}^{-1}\right)$} & \multirow{2}{*}{ Assignments } \\
\hline 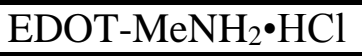 & $\mathrm{PEDOT}^{-\mathrm{MeNH}_{2}} \cdot \mathrm{HCl}$ & \\
\hline 921 & 937 & C-S-C deformation \\
\hline 1483 & 1512 & $\mathrm{C}=\mathrm{C}$ stretching \\
\hline 1195 & 1201 & C-O-C stretching \\
\hline 1359 & 1325 & C-C stretching \\
\hline 2819 & 2895 & $\mathrm{CH}_{2}$ vibration \\
\hline 3437 & 3475 & $\mathrm{NH}_{3}{ }^{+}$in-plane vibration \\
\hline 3005 & Absent & C-H vibration \\
\hline
\end{tabular}


Table 2

\begin{tabular}{cccccccc}
\hline \multirow{2}{*}{ Polymers } & $\begin{array}{c}\text { Wavelength } \\
(\mathrm{nm})\end{array}$ & $\begin{array}{c}T_{\text {red }} \\
(\%)\end{array}$ & $\begin{array}{c}T_{\text {ox }} \\
(\%)\end{array}$ & $\begin{array}{c}\Delta T \\
(\%)\end{array}$ & $\begin{array}{c}\text { Response time (s) } \\
\text { Oxidation }\end{array}$ & Reduction & $\begin{array}{c}C E \\
\left(\mathrm{~cm}^{2} \mathrm{C}^{-1}\right)\end{array}$ \\
\hline PEDOT- & 602 & 24.52 & 50.90 & 26.38 & 1.4 & 9.6 & 156 \\
$\mathrm{MeNH} \cdot \mathrm{HCl}$ & 1100 & 70.98 & 53.51 & 17.47 & 3.2 & 6.0 & 55 \\
$\mathrm{PEDOT}-$ & 582 & 24.8 & 66.6 & 41.8 & 2.4 & 3.6 & 152.1 \\
$\mathrm{MeNH}_{2}$ & 1050 & 70.2 & 33.3 & 36.9 & 5.2 & 9.8 & 91.0 \\
$\mathrm{PEDOT}$ & 585 & 24.77 & 78.50 & 54 & 0.36 & - & 137 \\
\hline
\end{tabular}

Tables:

Table 1 Assignments of FT-IR spectra of the monomer and the doped PEDOT$\mathrm{MeNH}_{2} \cdot \mathrm{HCl}$.

\begin{tabular}{ccc}
\hline \multicolumn{2}{c}{ Band $\left(\mathrm{cm}^{-1}\right)$} & \multirow{2}{*}{ Assignments } \\
\cline { 1 - 2 } EDOT-MeNH ${ }_{2} \cdot \mathrm{HCl}$ & PEDOT-MeNH${ }_{2} \cdot \mathrm{HCl}$ & C-S-C deformation \\
\hline 921 & 937 & C $=$ C stretching \\
1483 & 1512 & C-O-C stretching \\
1195 & 1201 & C-C stretching \\
2859 & 1325 & CH vibration \\
3437 & 2895 & $\mathrm{NH}_{3}{ }^{+}$in-plane vibration \\
3005 & 3475 & C-H vibration \\
\hline
\end{tabular}

Table 2 Electrochromic switching and optical absorbance monitored at $602 \mathrm{~nm}$ (A) and $1100 \mathrm{~nm}$ (B) profiles of PEDOT- $\mathrm{MeNH}_{2} \cdot \mathrm{HCl}$ film recorded during double step spectrochronoamperometry between $-0.5 \mathrm{~V}$ and $0.8 \mathrm{~V}$ for the switching time of $10 \mathrm{~s}$.

\begin{tabular}{cccccccc}
\hline \multirow{2}{*}{ Polymers } & $\begin{array}{c}\text { Wavelength } \\
(\mathrm{nm})\end{array}$ & $\begin{array}{c}T_{\text {red }} \\
(\%)\end{array}$ & $\begin{array}{c}T_{\text {ox }} \\
(\%)\end{array}$ & $\begin{array}{c}\Delta T \\
(\%)\end{array}$ & \multicolumn{2}{c}{ Response time (s) } & \multirow{2}{c}{$\begin{array}{c}C E \\
\left(\mathrm{~cm}^{2} \mathrm{C}^{-1}\right)\end{array}$} \\
\hline PEDOT- & 602 & 24.52 & 50.90 & 26.38 & 1.4 & 9.6 & 156 \\
$\mathrm{MeNH}{ }_{2} \cdot \mathrm{HCl}$ & 1100 & 70.98 & 53.51 & 17.47 & 3.2 & 6.0 & 55 \\
$\mathrm{PEDOT}-$ & 582 & 24.8 & 66.6 & 41.8 & 2.4 & 3.6 & 152.1 \\
$\mathrm{MeNH}_{2}$ & 1050 & 70.2 & 33.3 & 36.9 & 5.2 & 9.8 & 91.0 \\
PEDOT & 585 & 24.77 & 78.50 & 54 & 0.36 & - & 137 \\
\hline
\end{tabular}

